\title{
DO PRECARIO
}

\author{
SUMMARIO \\ $1 .^{0}-$ Natureza e genese do precario. \\ $20^{\circ}$-Quem póde ser rogans ou precarista. \\ $3 .^{\circ}-$ Quem póde ser rogatus. \\ $4 .^{\circ}$ - Como se constıtúe o precario. \\ $5 .^{\circ}$ - Come se extingue. \\ 6. ${ }^{\circ}$-Pontos de contacto e de differença \\ entre o precario e a doação. \\ 7.0_-Pontos de contacto e de differença \\ entre o precario e o commodato. \\ $8^{0}$-Acções relativas ao precario. \\ 9.0-Effeitos do precario.
}

\section{$\S 1 .^{\circ}$}

NatureZA E GENESE DO PRECARIo

1. Ensina a philosophia que o conhecimento do presente depende do conhecimento do passado, porque aquelle é este mesmo adaptado ás condições actuaes (Conf. meus Ensaios de philosophia do direito, pags. 29, 185 e 194).

Assim, para conhecer a natureza do precario, é mistér estudar a sua historia, partindo da genese do instituto e acompanhando-o nas mudanças porque tem passado até a actualidade.

2. Precarium, define Ulpiano, est, quod precibus petenti utendum conceditur tamdiu, quamdiu is qui concessit, patitur. Em vulgar: Precario é o que se 
concede a alguem, a seu pedido, para seu uso e goso, pelo tempo que ao concedente aprouver (Frag. $1 .^{\circ}$, princ., Dig., liv. 43, tit. 26, de precario).

O precario é uma das instituições romanas, qué remontam á mais alta antiguidade.

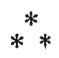

3. Começou por ser uma coisa extranha ao direito, por este desconhecida e não protegida. $\mathrm{O}$ antigo direito romano, o jus civile, reconhecia a existencia do precario, mas não como instituição juridica. Interdictum de precariis, diz Paulo, merito introductum est, quia nulla eo nomine jur is civilis actio esset. tinctas:

O solo romano era dividido em duas partes dis"

ager privatus $e$

ager publicus.

O ager privatus pertencia aos particulares, e

- ager publicus ao Estado. A propriedade deste era do Estado, e seu uso dos patricios, os quaes, rogados por seus clientes, foram-lhes concedendo, por favor, por liberalidade, partes do ager publicus para morarem e cultivarem, sem paga alguma, contentando-se com as vantagens consistentes nos obsequios, presentes e actos de subordinação por parte dos mesmos clientes.

A relação assim estabelecida entre os patronos e os clientes nada tinha de juridica: o patrono não tinha acção contra o cliente precarista, nem este contra aquelle ou contra terceiros. Não creava direito nem obrigação. Era um contracto bonae fidei, cujo cumprimento dependia só da boa vontade da parte obrigada, da sua consciencia, da sua lealdade ou do seu temor da opinião, (Veja-se em meus Ensaios citados, nota 91, pags. 129-31, a noção de contracto bonae fidei).

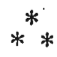

4. Si na phase do jus civile foi o precario extranho ao direito, na phase do jus gentium entrou elle para a esphera do direito, assumiu caracter juridico, 


\section{$-175-$}

como o exigiam as necessidades do tempo. E, pois, um instituto procedente do jus gentium. E isto está na lei: é o frag. $1 .{ }^{\circ}, \S 14$, Dig., liv. 43, tit. 26 , de precario, que diz:

Quod genus liberalitatis ex jure gentium descendit (Ülpiano).

5. Parece que, a principio, só se applicava aos immoveis, nota Maynz, çomo deixa ver o frag. $4 .^{\circ}$, Dig., de precario, que diz: In rebus etiam mobilibus precario rogatio constitit.

\section{$\S 2 .^{\circ}$}

QUEM PÓDE SER ROGANS OU PRECARISTA

1. Considera-se ter alguma coisa ou algum direito a titulo de precario aquelle que obteve a sua posse, para seu uso, exclusivamente mediante rogos seus: "Habere precario videtur, qui possessionem vel corporis vel juris adeptus est, ex hac solummodo causa, quod preces adhibuit, et impetravit, ut sibi possidere aut uti liceat», diz Ulpiano, no frag. $2 .^{\circ}, \S 3 .^{\circ}$, Dig., de precario.

2. Dois requisitos são, pois, necessarios para que alguem se repute ter uma coisa a titulo de precarista:

a) que a tenha obtido por via de rogos, de supplicas, preces adhibuit, quer por si mesmo directamente, quer por via de terceiro, precedendo mandato seu ou succedendo ratificação: «Si procurator meus, diz Ulpiano, me mandante, vel ratum habente, precario rogaverit, ego precario habere dicor». (Conf. Pothier, Pandectes de Justinien, vol. 18, pag. 83);

b) que só haja empregado rogos, preces, e não haja outra causa. Por isso, os hospedes e aquelles, que recebem habitação gratuita, não se reputam habitar 
a titulo de precario: "Hospites, diz Pomponio, et qui gratuitam habitationem accipiunt, non intelliguntur precario habitare».

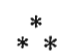

3. Entretanto, cumpre notar que aquelle que possuia a coisa por causa diversa dos rogos ou sem causa, considera-se possuil-a precariamente, e só a este titulo, desde que pediu que assim lhe fosse concedido possuir-ex quo rogavit aliquem ut eam possideret, incipit videri hanc precario possidere, et ex aliis causis possidere desinit, diz Pothier.

$\mathrm{E}$ isto é expresso no frag. $6 .^{\circ}, \S 3 .^{\circ}$, Dig., de precario, onde diz Ulpiano:

"Julianus ait eum, qui vi alterum dejecit, et ab eodem precario rogavit, desinere vi possidere, "et incipere precario; nec existimare, sibi ipsum causam possessionis mutare: cum voluntate ejus, quem dejecit, coeperit precario possidere, nam si ab eodem emisset, incipere etiam pro emptore posse dominium capere".

Em vernaculo:

«Diz Juliano que aquelle que espoliou outrem da posse e depois obteve deste o immovel a titulo de precario, deixa de possuir a titulo de violencia e começa a possuir a titulo de precario; e nem se póde dizer que elle mudasse a si mesmo o titulo da posse, quando começou a possuir a titulo de precario por vontade daquelle que por elle havia sido espoliado, porque si o mesmo houvesse adquirido esse immovel por compra, começaria a possuil-o a titulo de comprador e assim poderia adquirir a propriedade por prescripção».

Com este texto está accorde um outro de Venuleio, que é o frag. 22:

«Si is qui pro possessore possideret, precariò dominum rogaterit ut sibi retinere rem liceret, vel is qui alienam rem emisset, dominum rogaverit: apparet eos precariò possidere, nec existimandos mutare sibi causam possessionis, quibus a domino concedatur precariò possidere. 


\section{$-\mathrm{I} 77-$}

Nam et si id quod possideas, alium precariò rogaveris, videri te desinere ex prima causa possidere, et incipere ex precariò habere.

Et contra si possessorem precariò rogaverit, qui rem avocare ei posset, teneri eum precariò : quoniam aliquid ad eum per hanc precarii rogationem pervenit, id est, possessio quae aliena sit».

Em vernaculo:

«Si aquelle que possuia uma coisa como possuidor, rogou ao dono que lhe permittisse retel-a a titulo de precario, ou si aquelle que comprou a coisa a quem não era dono, fez o mesmo rogo ao proprietario, parece que elles possuem precariamente, e nem se póde pretender que hajam mudado o titulo de sua posse aquelles que assim possuem.

Com effeito, si rogaste que te fosse concedido possuir precariamente aquillo que possuias por outro titulo, deixas de possuir pela primeira causa, e começas a possuir a titulo de precario.

$\mathrm{E}$, por outro lado, si aquelle que possue, pediu á pessôa, que podia rehaver a coisa, que lhe concedesse possuir precariamente, fica sujeito á acção de precario, porque adquiriu por esta convenção uma posse que não tinha, isto é, a de uma coisa que não pertencia áquelle de quem o mesmo a houvera».

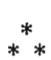

4. Ha, porém, um texto que parece contrariar a doutrina exposta. É ofrag. $4 .^{\circ}, \S 2 .^{\circ}$, Dig., de precario, em que diz Ulpiano:

"Tenetur hoc interdicto non utique ille qui precario rogavit, sed qui precario habet. Etenim fieri potest, ut quis non rogavit, sed habeat precario: utputa servus meus rogavit, mihi adquisivit precarium; vel quis alius qui juri meo subjectus est.»

Em vernaculo:

«Nem sempre é obrigado por este interdicto aquelle que pediu a coisa a titulo precario, mas aquelle que a tem a este titulo, pois póde acontecer que quem não 
pediu a coisa a tenha, entretanto, a titulo precario. Assim, si meu escravo ou qualquer outra pessôa sujeita a meu poder, pediu a coisa, adquire para mim o precario».

Mas não a contraria: os actos daquellas pessôas alieni juris eram tidos em direito como do paterfamilias.

Finalmente, cumpre accrescentar que quem obtem a titulo precario a permissão para morar num immovel, a obtem implicitamente para si e os seus.

E esta clausula é subentendida. Isto é expresso no frag. 21 , Dig., liv. 43, tit. 26 , de precario, onde Venuleio diz:

"Cum precario quis rogat ut ipsi in eo fundo morari liceat, supervacuum est adjici, ipsi, suisque: nam per ipsum suis quoque permissum uti videatur".

Em vernacúlo:

"Quando se obtem, a titulo de precario, a permissão de morar em um immovel, é desnecessario accrescentar a clausula-para si e os seus, porquanto, esta clausula é subentendida»

$\S 30^{\circ}$

QUEM PÓDÉ SER ROGATUS OU CONCEDENTE

1. Póde ser rogatus ou concedente:

a) o proprietario e

b) o possuidor.

Indubitavelmente 0 proprietario de uma coisa póde dal-a a alguem, a titulo de precario. E' o que se vê no frag. 18, Dig., de precario, onde Juliano diz:

"Unusquisque potest rem suam, quamvis non possideat, precariò dare ei, qui possideat».

Em vernaculo:

"Póde cada um, embora não possúa sua coisa, dal-a a titulo de precario a quem a possua ».

Deste texto se vê mais que, para conceder a coisa a titulo de precario, não é mistér que o rogatus ou concedente tenha a posse della. $\mathrm{E}$ isto é confirmado pelo citado frag. 22, como de seu contexto bem se vê. 


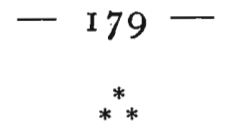

2. Mesmo quem não é proprietario, mas possuidor, póde dar a coisa a titulo de precario, como acontece no caso do penhor, quando o credor, possuidor da coisa empenhada, concede-a a titulo de precario a seu dono, o devedor. E' o que está no frag. $6 .^{\circ}, \S 4,^{\circ}$, de Ulpiano, liv. 43, tit. 26 , de precario:

"Quaesitum est, si quis rem suam pignori mihi dederit, et precario rogaverit, an hoc interdictum locum habeat; quoestio in eo est, ut precarium consistere rei suae possit? Mihi videtur verius, precarium consistere in pingnore: cum possessionis rogatur, non proprietatis; et est haec sententia etiam utilissima: quotidie enim precario rogantur creditores ab his, qui pignori dederunt: et debet consistere precarium»

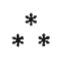

3. Convém notar de passagem que esta disposição é de excepção, porque a regra é o proprietario não poder possuir a sua coisa a titulo de precario, pois tem a posse isenta de precariedade. Desta regra dá noticia Ulpiano, no frag. $4 .^{\circ}, \S 30^{\circ}$, Dig., de precario: "Item si rem meam precario rogavero, rogavi quidem precario, sed non habeo precario: idcirco quia receptum est, rei suae precarium non esse.»

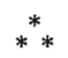

4. E cumpre observar que o precario póde ser concedido pelo escravo da pessoa a quem compete fazer tal concessão, uma vez que o senhor do escravo ratifique o seu acto. E' o que consta do frag. $19, \S 1 .^{\circ}$, Dig., liv. 43, tit. 26, de precario, onde diz Juliano: "Qui servum meum precario rogat, videtur a me precario habere, si hoc ratum habuere. et ideo precario interdicto mihi tenebitur».

E a razão é que, sendo o escravo havido como coisa, res, caput non habet, e seus actos. se reputam do senhor, si este os ratifica. 


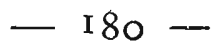

$\$ 4 \cdot^{\circ}$.

Como se constitue o PRECARIO

1. O precario não se constituia pelos modos do antigo jus civile, a

\section{mancipatio e a}

in jure cessio,

simulacro de venda e simulacro de reivindicação, porque, como vimos, não foi elle reconhecido nem protegido pelo jus civile: ex jure gentium descendit, na phrase de Ulpiano, frag. $1 .^{\circ}, \S 10^{\circ}$, do citado tit. Seus modos de acquișição ou constituição pertencem ao direito pretoriano, depois fundido com o jus civile, formando um só organismo juridico, na ultima phase da evolução do direito romano.

\section{$*^{*} *$}

2. Podia ser constituido por qualquer fórma: não havia uma fórma sacramental para sua acquisição. Podia ser por escripto, verbalmente, entre ausentes, como entre presentes. E' o que se verifica do frag. 9.', onde ensina Gaio:

«Precaria possessio constitui potest vel inter praesentes, vel inter absentes: veluti per epistolam, vel per nuntium».

E póde até ser constituido tacitamente. E' o que deixa ver um texto de Paulo, citado por Pothier: «Interdum et tacitè precarium constituitur, diz Pothier. E accrescenta:

"Hinc Paulus: Precario possidere videtur, non tantum qui per epistolam, vel quacumque alia ratione hac sibi concedenti postulavit; sed et is qui nullo voluntatis indicio, patiente tamen domino, possedit». Este texto é das sentenças de Paulo. Pothier, vol. 18, pag. 87. E esta doutrina encontra apoio em texto positivo: é o frag. $4 .^{\circ}, \S 4 .^{\circ}$, de precario, onde diz Ulpiano:

"Item qui precario ad tempus rogavit, finito tempore, etiamsi ad hoc temporis non rogavit, tamen 
precario possidere videtur intelligitur enim dominus, cum patitur eum, qui precario rogaverit, possidere, rursus precario concedere».

\section{$\S 5 .^{\circ}$ \\ Como se extingue.}

1. A regra geral, tirada da propria natureza do precario, é que elle cessa, quando assim o quer o rogatus. E' o que deixa ver a noção legal:

"Precarium est, quod precibus petenti utendum conceditur tamdiu, quandiu is, qui concessit, patitur».

2. Ha, porém, casos particulares de cessação do precario, que merecem menção no direito. Assim, si o precario foi concedido por um certo tempo, cessa findo esse tempo. E' o que prova o frag. 5.०, de precario, onde diz Pomponio :

"Sed si manente adhuc precario, tu in ulterius tempus rogasti, prorogatur precarium; nam nec mutatur causa possessionis, et non constituitur eo modo precarium: sed in longius tempus profertur. Si vero praeterita die rogas, propius est, ut soluta jam causa precarii non redintegretur, sed nova constituitur».

$$
*^{*} *
$$

3. Extingue-se tambem o precario, quando foi concedido sob uma condição que se verificou. Por exemplo: Si alguem vende uma coisa com a condição de ficar em poder do comprador, a titulo de precario, até ser pago o preço no tempo convencionado, e este preço não é pago, cessa o precario. E' o que diz o frag. 20, de Ulpiano:

«Ea, quae distracta sunt, ut precario penes emptorem essent, quoad pretium universum persolveretur, si per emptorem stetit, quo minus persolveretur, venditorem posse consequi».

$$
*^{*} *
$$

4. O precario extingue-se igualmente si o precarista passa a possuir a coisa por outro titulo. E' o que 
consta de um texto de Ulpiano, que faz o frag. 10, princ., Dig., liv. 41. tit. 2. ${ }^{\circ}$, de adquirenda vel amittenda possessione, que diz:

«Si quis ante conduxit, postea precario rogavit, videbitur discessisse a conductione; quod si ante rogavit, postea conduxit, conduxisse videbitur; potius enim hoc procedere videtur, quod novissimo factum est; et hoc Pomponius ait».

$$
\text { ** }
$$

5. Extingue-se ainda pela morte do rogans, não pela do rogatus: é o que prova o frag. $12, \S 1 .^{\circ}$, Dig., de precario, onde Celso diz:

"Precario rogatio et ad heredem ejus, qui concessit, transit, ad heredem autem ejus, qui precario rogavit, non transit. quippe ipsi dumtaxat, non etiam heredi concessa possessio est».

$$
\S 6 .^{\circ}
$$

Pontos de CONTACTO E DE DIFFERENĢA ENTRE

O PRECARIO E. A DOACÇAO.

1. O ponto de contacto mais saliente é o caracter de liberalidade de ambos os institutos: tanto para o rogatus, como para o doador, o acto é de beneficencia; ha sempre uma datio. Isto se vê do frag. $1 .^{\circ}$, $\S 1 .^{\circ}$, de precario, onde diz Ulpiano, logo após a definição de precario: cendit».

"Quod genus .liberalitatis ex jure gentium des-

2. Vejamos o ponto de differença. Quem dá a coisa por doação, dá para nunca mais rehaver. Quem a dá a titulo de precario, dá para rehaver, quando lhe aprouver. E' o que consta do frag. $1 .^{\circ}, \S 2 .^{\circ}$, onde ensina Ulpiano, depois de haver dito que o precario ex jure gentium descendit:

"Et distat a donatione, eo quod qui donat, sic dat, ne recipiat; at qui precario concedit, sic dat, quasi tunc recepturus, cum sibi libuerit precarium solvere». 
$\S 7 .^{\circ}$.

PonTOS DE CONTACTO

E DE DIFFERENÇA ENTRE O PRECARIO E O COMMODATO

1. Pontos de contacto. O commodato é o contracto pelo qual um dos contrahentes entrega ao outro a coisa, para della fazer uso determinado, por um tempo determinado, e gratuitamente. O caracter beneficente é, pois, o ponto de contacto que se põe em relevo. Outro ponto de contacto entre esses institutos é que em nenhum delles se verifica a transmissão da propriedade.

E ha texto expresso a respeito, que é o frag. $1^{\circ}$, $\S 3 .^{\circ}$, Dig, de precario, onde diz Ulpiano:

"Et est simile commodato. nam et qui commodat rem, sic commodat, ut non faciat rem accipientis; sed ut ei uti commodata permittat».

\section{$*^{*} *$}

2. Pontos de differença. Ha varios. Um delles é que no commodato ha prazo, e no precario não ha. Eis o que se vê do frag. 12, Dig., de pracario:

"Cum precario aliquid datur, si convenit, ut kalendas julias precario possideat: nunquid exceptione adjuvandus est, ne ante ei possessio auferatur? Sed nulla vis est hujus conventionis, ut rem alienam domino invito possidere liceat.»

$\S 8 .^{\circ}$

ACÇ̃Es RELATIVAS AO PRECARIO

$\mathrm{O}$ rogatus tem contra o rogans um interdicto $\mathrm{e}$ uma acção. 'E' o interdicto de precario e a acção praescriptis verbis. E' o que se vê do frag. $2 .^{\circ}$, princ., Dig., de precario, onde Ulpiano diz:

"Ait praetor: quod precario ab illo habes, aut dolo malo fecisti, ut desineres habere, qua de re agitur, id illi restituas".

E, no $\S 1 .^{\circ}$, accrescenta:

«Hoc interdictum restitutorium est. Et naturalem habet in se aequitatem: namque precarium revocare volenti competit». 


\section{$-\mathrm{I} 84-$ \\ $*^{*} *$}

2. A acção praescriptis verbis é concedida pelo $\S 2 .^{\circ}$ desse frag., ibi.

"Non solum hoc interdicto uti possumus, sed etiam praescriptis verbis actione, quae ex bona fide. oritur».

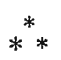

3. Cumpre notar que ao precarista assiste ainda o interdicto uti possidetis, ut frag., 17, Dig., de precario:

"Qui precario fundum possideat, is interdicto uti possidetis adversus omnes, praeter eum quem rogavit, uti potest».

Este interdicto tem por fim proteger a sua posse.

$\S 9 .^{\circ}$

EFFEITOS DO PRECARIO

O precario dá a posse ao precarista. E' o que consta de textos expressos. O frag. $13, \S 11^{\circ}$, de Gaio, Dig., de publiciana in rem actione, diz:

"Interdum quibusbam nec ex justis possessionibus competit publicianum judicium: namque pigneratitiae, et precariae possessiones justae sunt, sed ex his non solet competere tale judicium illa scilicet ratione, quia neque creditor, neque is, qui precario rogavit, "eo animo nanciscitur possessionem, ut credat se dominum esse».

O frag. $7 .^{\circ}, 4^{\circ}$, de Ulpiano, Dig., liv. 10, tit. $3 .^{\circ}$, communi dividundo, confirma-o nestes termos:

"Inter praedones autem hoc judicium locum non habet: nec, si precario possideant, locum habebit nec, si clam, quia iniusta est possessio ista. precaria vero, justa quidem, sed quae non pergat ad judicii vigorem».

O frag. $15, \S 4 .^{\circ}$, de Pomponio, Dig., de precario, vem corroborar o asserto:

«Eum qui precario rogaverit, ut sibi possidere liceat, nancisci possessionem non est dubium.» 
De accôrdo, o frag. $4 .^{\circ}, \S 1 .^{\circ}$, de Ulpiano, Dig., de precario:

"Meminisse autem nos oportet, eum qui precario habet, etiam possidere».

Não discrepa o frag. $2{ }^{\circ}, \S 3 .^{\circ}$, do mesmo Ulpiano, de precario, que diz:

«Habere precario videtur, qui possessionem vel corporis, vel juris adeptus est ex hac solummodo causa, quod preces adhibuit, et impetravit, ut sibi possidere aut uti liceat».

No mesmo sentido, o frag. 12, princ., desse titulo.

"Cum precario aliquid datur, si convenit, ut in kalendas Julias precario possideat»

E mais o frag. 17 de Pomponio:

"Qui precario fundum possidet, ex interdicto uti possidetis adversus omnes, praeter eum, quem rogavit, uti potest».

Concorda o frag. 19, de Juliano:

"Duo in solidum precario habere non magis possunt, quam duo in solidum vi possidere, aut clam: nam neque justae, neque injustae possessiones duae concurrere possunt». tituli:

E mais o frag. 22, princ., de Venuleio, hujus

"Si is, qui pro possessore possideret, precario dominum rogaverit, ut sibi retinere rem liceret; vel is, qui alienam rem emisset, dominum rogaverit apparet eos precario possidere; nec existimandos mutare sibi causam possessionis, quibus a domino concedatur precario possidere».

E, no $\S 1 .^{\circ}$, accrescenta:

"Si pupillus sine tutoris auctoritate rogaverit, Labeo ait habere eum precariam possessionem».

Muitos outros textos da legislação romana provam que o precarista possúe. E a sua posse, aliás, é uma posse ad interdicta, e não ad usucapionem.

Dr. Jose Mendes 